\title{
A review on the development of wind turbine generators across the world
}

\author{
N. Goudarzi · W. D. Zhu
}

Received: 23 May 2013 / Accepted: 27 May 2013 / Published online: 20 June 2013

(C) Springer-Verlag Berlin Heidelberg 2013

\begin{abstract}
Wind power as a source of green and abundant energy is proposed as one of the main new world power sources and has acquired a great momentum across the world. In the last few decades, wind turbines with different generators have been developed to increase the maximum power capture, minimize the cost, and expand the use of the wind turbines in both onshore and offshore applications. This paper reviews the development of different types of wind turbine generator technologies and discusses advantages and disadvantages of each type. In addition, a comparison of different generator designs based on the technical data and market trends is provided. To better understand the development of generator concepts on the market, the market trends of current large generators with a capacity of $2.5 \mathrm{MW}$ and above across the world are evaluated.
\end{abstract}

Keywords Induction generators · Synchronous generators $\cdot$ Permanent magnet generators . High-temperature-superconducting generators . Wind power generation - Onshore/offshore wind turbines . Power electronics $\cdot$ Power quality $\cdot$ Wind farms

\section{Introduction}

In recent years, implementing renewable energies has moderate to strong support across the world. Some types of renewable energies such as hydropower are considered to be fully

N. Goudarzi · W. D. Zhu (凶)

Department of Mechanical Engineering, University of Maryland,

Baltimore County, Baltimore, MD 21250, USA

e-mail:wzhu@umbc.edu

N. Goudarzi

e-mail: navid2@umbc.edu developed, and others such as solar power are limited to specific regions [1]. Wind power has been used for more than two thousand years; windmills were capturing wind power since $200 \mathrm{Bc}$ using a constant speed rotor assembly [2]. Wind power as a free, abundant, globally available, and green energy source is an obvious choice among all renewable energy sources for generation of electricity [3].

Figure 1 shows the world's total cumulative installed wind power capacity between 1991 and 2012, and Fig. 2 shows the shares of five continents in the total installed wind power capacity between 2002 and 2012 [1,4-7]. The average annual growth in the total installed wind power capacity in the last ten years has been $25 \%$ per year, and it is expected that the cumulative installed wind power capacity would pass $400 \mathrm{GW}$ by 2015 . It is also anticipated that $12 \%$ of the world's electricity consumption will be provided by wind power by 2020 [7].

Europe has the most share of the total installed wind power capacity since 1997, with an increase from 4.6 GW in 1997 [1] to more than $102 \mathrm{GW}$ in 2012. While Oceania and South America have the minimum wind power capacity increase from 2002 to 2012, the total installed capacity in Asia has a remarkable growth from $1.1 \mathrm{GW}$ in 1997 [1] to more than $100 \mathrm{GW}$ in 2012 that will make it the pioneer in the total installed wind power capacity, ahead of Europe in the following years.

Figure 3 shows the top 12 countries in the world with the largest wind power capacities among more than 97 countries that use wind power on a commercial basis as of 2012 [79]. The significant growth in the total installed wind power capacity in Asia is mainly due to the rapid increase in the wind power capacity in China, which had an increase from $5.9 \mathrm{GW}$ in 2007 to almost $76 \mathrm{GW}$ in 2012, with a considerable difference from the second ranked country, the United States of America (USA). While Germany still has the largest wind 
Fig. 1 World's cumulative installed wind power capacity during 1991-2012
Fig. 2 Continents' shares of wind power capacity during 2002-2012
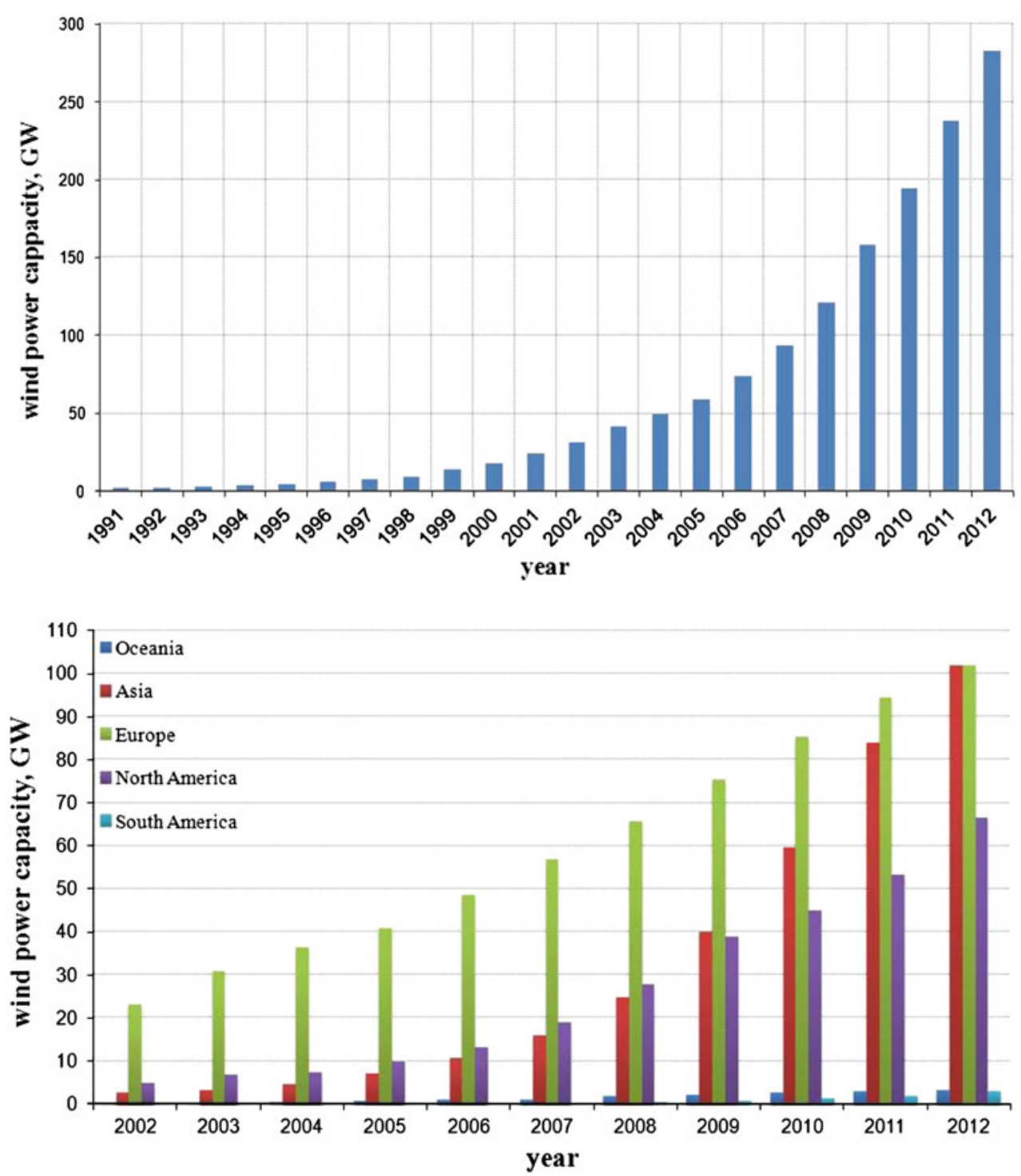

power capacity in Europe, there has been a very low rate of installed wind power capacity increase since 2007, compared with China and the USA, and it became the country with the third largest annual wind power capacity.

A wind turbine converts the captured kinetic energy in the wind to electrical energy by means of a generator. Generators with more reliable, efficient, and compact designs should be used in wind turbines to maximize the wind power capture and produce a higher quality output power. To determine the appropriate generator designs for onshore and offshore wind turbines, different types of wind turbine generators that have been studied in the literature are discussed in this paper, with the criteria based on the speed range, cost, weight, size, and power quality at the grid connection. Also, the wind turbine generators are compared, and advantages and disadvantages of different designs are summarized with more extensive criteria. Consequently, a generator concept that has a greater performance over all other generators can be obtained. In addition, to evaluate market shares of different generator concepts that are used in large capacity wind turbines, the market and technology trends of large wind turbine generators with a capacity of $2.5 \mathrm{MW}$ and above across the world are provided.

\section{Electric machines}

Electric generators can be classified based on the application domain that implies the power level and principles of operation [10]. This work categorizes generators based on the principles of operation. Figure 4 shows various types of electric machines, ranging from DC electric generators to new state-of-the-art high-temperature-superconducting (HTS) generators [10-12]. The main focus of this paper is on the AC poly-phase group, which is the main concept used in the wind power industry. 
Fig. 3 Top 12 countries with the largest annual wind power capacities during 2007-2012
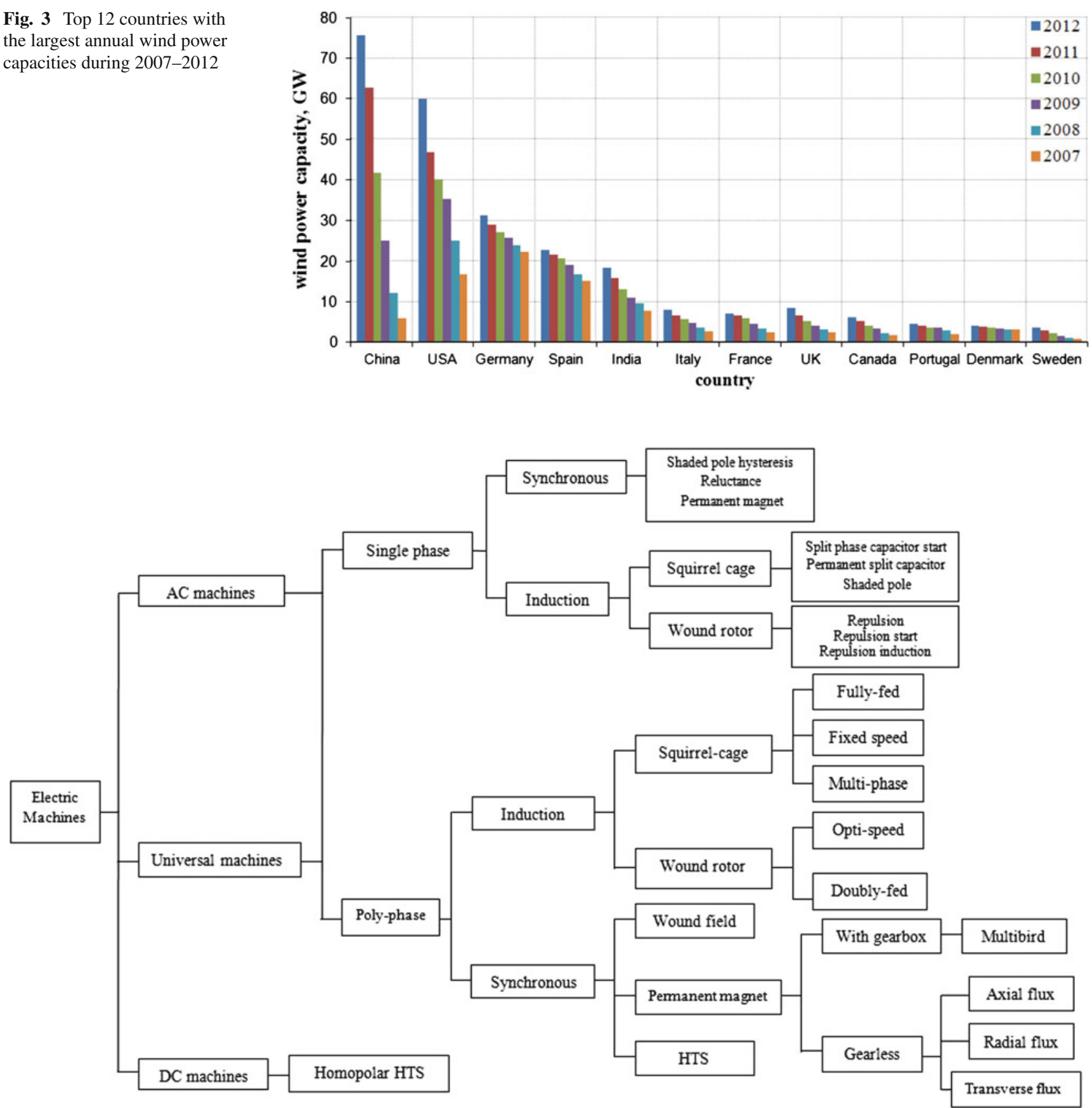

Fig. 4 Electric machine diagram

\subsection{Induction generator}

\subsubsection{Squirrel-cage induction generator (SCIG)}

A SCIG has been the most popular generator type of fixed speed stall control wind turbines for a long time [13]. The advantages of a SCIG are inexpensive mass production of the generators with a robust and easy technology and its direct connection to the grid [13-15]. However, the speed of a SCIG has a limited range of variation and is not controllable. The
SCIG has a multiple-stage gearbox, and it always consumes reactive power that is not controllable [13].

\subsubsection{Doubly-fed induction generator (DFIG)}

The increase in the captured power level, the grid requirement for good power quality, and the requirement for reducing the noise level and the mechanical stress of the drivetrain resulted in initiating the variable speed operation in the late 1990's and introducing DFIGs [2]. The operation principle 
of a DFIG is the same as that of a SCIG, but a DFIG rotor has a three-phase winding instead of a squirrel-cage rotor in the SCIG. The DFIG has a sufficient range of variable speed by controlling the active power flow direction, and the reactive power can be controlled by the rotor current in the converter [14]. Brushes and the multiple-stage gearbox in a DFIG require regular maintenance and have a potential cause of machine failure. Its output is connected to the grid through expensive power electronic converters that are very sensitive to over currents. In addition, the control strategies in case of grid disturbances are very complex $[14,16,17]$.

\subsection{Synchronous generator (SG)}

SGs with new state-of-the-art designs are coming back to the market and become a competitive design for induction generators [18-20]. Fixed speed SGs have been used in some wind turbines [21]. Multi-phase SGs with different designs, such as DC current excited rotors, claw-pole electrically excited rotors, permanent magnet (PM) rotors, and variable reluctance rotors, have been developed [10]. SGs with a DC current excited rotor and a PM rotor are described here.

Variable speed gearless wind turbines usually use low speed, high torque SGs. The rotor of a direct drive (DD) generator is directly connected to the hub of the rotor blades [15]. Thus, the DD generator rotates at a lower rotational speed that makes it necessary to produce a higher torque compared with a regular generator connected to a gearbox system. To eliminate the need for a gearbox, a DD machine has been made with a large number of poles to control the generator speed over a wide range, even at very low speeds, which results in a heavier and larger diameter generator. However, the manufacturing cost and the generated noise and pollution are reduced, and the required regular maintenance besides the potential cause of mechanical failure of the gearbox is eliminated [22-29]. Thus, the DD machine becomes a competitive solution despite a higher start-up cost. Note that either a minimum size at the rated power factor with the given efficiency, or a maximum efficiency at the rated power factor with the given size are desired in designing a generator with given mechanical specifications [30].

DD SGs are usually equipped with a three-phase winding on the stator; they have either a rotor winding supplied by a DC current from a separate circuit, which are called electrically excited (or wound field) SGs (EESGs), or PMs attached to the rotor, which are called PM SGs (PMSGs).

\subsubsection{EESG}

The EESG was first introduced with a $500 \mathrm{~kW}$ variable speed DD wind turbine by Enercon of Germany in 1992 [31]. The EESG stator is the same as that of the induction machine carrying a three-phase winding; its rotor may have salient poles that are usually used in low speed machines or may be cylindrical [32]. The amplitude and frequency of the voltage at the generator side of an EESG converter can be fully controlled by the converter, independently of the grid characteristics [14]. Compared with a PMSG, an EESG does not require PMs; it will reduce a large fraction of the generator cost and makes it the most used generator type of large DD wind turbines [14]. One drawback of an EESG is the necessity of exciting its rotor winding by a DC current source using brushes and slip rings or a rotating rectifier without using brushes. Expensive power electronic components and the requirement of intensive cooling are among other drawbacks of an EESG. An EESG usually has a large rotor diameter. For instance, the Enercon E-126 wind turbine, which is the largest onshore wind turbine $(7.58 \mathrm{MW})$ built to date, has a rotor diameter of $126 \mathrm{~m}$. The very large diameter makes the transportation and installation difficult.

\subsubsection{PMSG}

The most promising PM machine category deals with DD wind turbines [33]. General Electric (GE), Zephyros, Mitsubishi, and Siemens are among manufacturers that implement PMSGs in their wind turbine designs. The rotor in a PMSG is replaced with PMs; the excitation is provided by PMs instead of the field winding, but the stator winding is the same as that of a three-phase EESG [28]. PMSGs have several advantages over EESGs, including smaller rotor diameters, higher reliability due to elimination of different mechanical components such as slip rings, better thermal characteristics, and lower mass per kilowatt output power $[12,31,34,35]$. Lower weight in PMSGs is achieved by such modifications as eliminating the gearbox, and providing a larger airgap that reduces flux linkage and results in a smaller generator size with respect to the wind turbine power rating [31]. Other advantages of DD PMSGs are discussed in the literature [2325,28,36-38]. High cost of PMs, manufacturing and assembling, and demagnetization of PMs at high temperatures are among main drawbacks of a PMSG $[12,31,33,39,40]$. In recent years, improvements in the PM performance and the cost reduction have made them more attractive than before. In the case of a converter fault in a PM machine, the machine counter electromagnetic force feeds the fault and causes dangerous torque pulsation [41]. To maintain the transient stability of a PMSG and avoid the risk of wind turbine mechanical runaway during fault conditions, more robust control strategies are recommended [12].

Figure 5 shows the design options for PMSGs used in DD wind turbines, which can be categorized into three groups: axial flux (disk type), transverse flux, and radial flux (drum type) $[12,14]$. The radial flux design is usually used for DD PMSGs, transverse flux machines are not available on the market, and the axial flux design has only been used in low 
Fig. 5 Design options for PMSGs in DD wind turbines

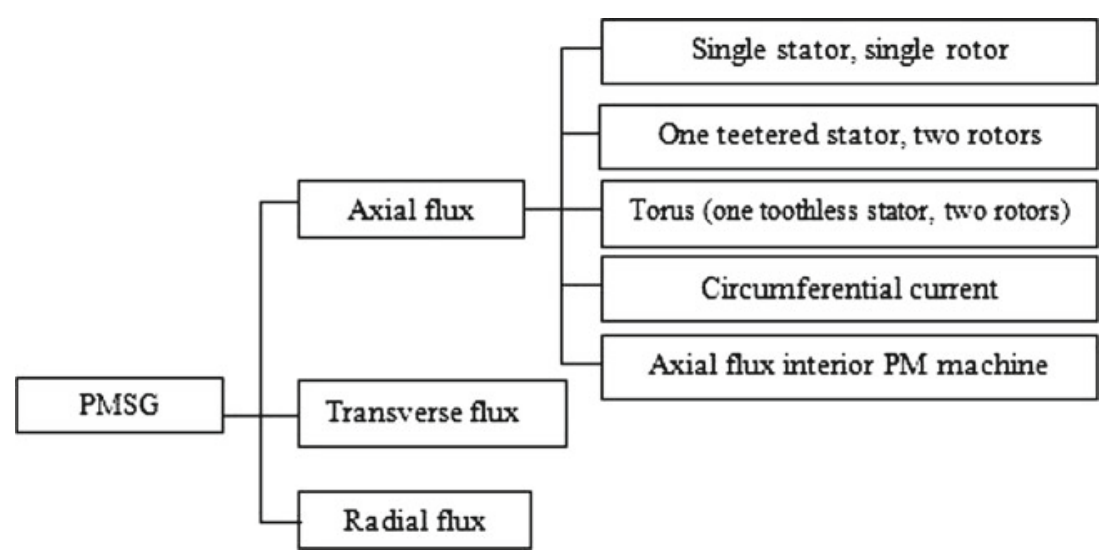

power machines [12]. Detailed designs of these variations can be found in the literature $[12,25,36,39,42]$.

Two manufacturers, Multibird of Germany/France [31, 43] and WinWind of Finland [31], have combined a DD PM wind turbine generator with a single-stage gearbox, which has a simpler gearbox design and higher efficiency compared with a three-stage geared wind turbine, with a full converter that has more flexibility at both 50 and $60 \mathrm{~Hz}$ frequencies.

\subsubsection{HTS SG}

Studying the application of HTS materials in rotating machines has started since the late 1980s [44,45]. Bulk HTS materials, HTS wires, and a combination of them can be used in HTS machines [45-49]. HTS rotating machines with synchronous, homopolar, and induction configurations have been proposed and studied in the literature [50,51]. It has been several years since the second generation of superconducting materials with HTS wires has been introduced to the market. Having wind turbines operating at lower rotational speeds and eliminating gearboxes can be achieved by implementing generators equipped with HTS wires [45]. There are some wind turbine manufacturers developing HTS SGs. GE has started developing a $100 \mathrm{MW}$ two-pole SG that uses a HTS field winding [12]. The Windtec Solution Company has revealed its goal of designing and manufacturing a $10 \mathrm{MW}$ wind turbine (SeaTitan) using a HTS generator [52]. Note that HTS generators have other applications besides wind turbines; for instance, a $4 \mathrm{MW}, 6,600 \mathrm{~V}$ synchronous HTS generator for ship applications has been made by Siemens [12]. The new generations of HTS wires guarantee lower cost than the first generation wires (about $25 \%$ of the projected cost of the first generation wires $[12,44])$, which is a key factor in making the second generation of HTS wires economically feasible for use in wind turbine generators. HTS windings can operate at very high temperatures (more than $30 \mathrm{~K}$ ) and can be cooled with low cost and reliable off-theshelf refrigerators $[46,47]$. Higher power densities can be obtained due to the use of HTS wires in the field winding of SGs. HTS wires provide higher current densities (up to $200 \mathrm{~A} / \mathrm{mm}$ compared with about $5 \mathrm{~A} / \mathrm{mm}$ in EESGs [12]), which reduces the space required for the rotor field winding [12,44-47]. Lewis et al. [44] have studied HTS generators for DD wind turbines and shown that the ability of placing more turns of field winding in a small volume makes it possible to increase the airgap flux density of a HTS generator and consequently allows the airgap shear stress to increase. Thus, the advantages of a DD wind turbine generator in enhancing the power rating without any concern in increasing the size and mass of the generator can be achieved. The higher flux density of a HTS SG compared with a DFIG and a PMSG results in a weight reduction by four times and two times, respectively [12]. More details on the application of HTS wires in rotating machines can be found in the literature, which indicates that HTS generators with a more affordable and robust design are more efficient, lighter, and more compact compared with all other generators $[12,31,32,44-51,53]$.

\section{Generator system comparison}

Comparison of various types of wind turbine generators has been discussed by a number of researchers [14,20,2428,31,33,37,42,54-57]. Ameli et al. [20] have studied the feasibility of replacing induction generators with SGs in wind farm power stations and shown the advantages of PMSGs in terms of the efficiency, cost, size, and grid connection compared with the current induction generators. Comparison of induction generators with PMSGs for variable speed wind turbines has also been studied by Soens [14], Poore and Lettenmaier [27], Li and Chen [38], and Chen et al. [55]. Gupta et al. [31] have studied various converter options for PMSGs. Polinder et al. [28] have compared the main performance parameters of SCIGs and DD PMSGs at two different rated powers of $500 \mathrm{~kW}$ and $3 \mathrm{MW}$; the comparison shows the PMSG concept involves a larger generator size, higher drivetrain efficiency, and lower drivetrain weight compared with the SCIG one. Table 1 provides a performance comparison of different generators (SCIG, DFIG, multi-phase 
induction generator (MPIG), fixed speed SG, PMSG, EESG, and HTS generator) for large capacity wind turbine applications; the comparison is indicated by different symbols ranging from excellent to poor. There are some factors, such as the speed range of a generator, that are not a concern in the new generator design anymore; SCIGs with a limited speed range were mostly manufactured between the 1980s and 1990s. The gearbox requirement has been eliminated by introducing DD wind turbines. While DD wind turbines with PMSGs or EESGs are more reliable and efficient, and need less maintenance due to elimination of the gearbox system, they are larger and more expensive than geared wind turbines. The DD wind turbines with PMSGs have been designed to be made in a smaller size with a lower cost compared with those with EESGs. The results of studying suitable generator concepts for DD wind turbines by Bang et al. [37] show the superiority of DD PMSGs with a one-stage gearbox compared with SCIGs, DFIGs, and EESGs in terms of power loss, the energy yield, and the ratio of the annual energy yield to the cost of the drivetrain. Lewis et al. [46] have shown that the high cost of HTS generators for DD wind turbines can be overcome by using the second generation of HTS wires. A comparison of the performance and size of an induction generator with a HTS generator is provided by Schiferl et al. [45], which shows a higher efficiency and a smaller size of the HTS generator compared with an induction generator at the same rated power. The higher efficiency and lower loss in a HTS machine have been achieved by using less material.
Based on the performance of different generator concepts described in Sect. 2, and by comparing the advantages and disadvantages of different types of generators, it seems that HTS generators have the best potential compared with all other generators used in larger capacity wind turbines. The main concern that is associated with the high cost of a HTS generator seems to be controllable after introducing the second generation of HTS wires, which makes the technology economically viable for wind turbine applications.

Table 1 should be modified based on the importance of different parameters in certain applications. Different technical, environmental, and economical aspects should be considered to better evaluate various types of wind turbine generators for specific applications. For instance, while factors such as maintenance-free, smaller size, simpler structure, and higher reliability are essential in offshore wind turbine applications, the noise level has less importance compared with onshore wind turbine applications. The annual wind speed/direction distribution and the wind turbine hub height are among other parameters that can affect the performance of a wind turbine.

\section{Wind turbine generator trend}

The shares of different wind turbine generator concepts are investigated in the literature [4-9,15,57]. Market interest in SCIGs has decreased since the 1990s, except for some temporary intervals, and has had its minimum since 2003 when DFIGs overtook the market [4]. Use of wound rotor

Table 1 Performance comparison of different generator concepts

\begin{tabular}{llllllll}
\hline Factor & SCIG & DFIG & MPIG & SG & EESG & PMSG & HTSG \\
\hline Torque density & $\mathrm{P}$ & - & + & - & $\mathrm{P}$ & + & $\mathrm{E}$ \\
Speed range & $\mathrm{P}$ & + & + & + & $\mathrm{E}$ & + & $\mathrm{E}$ \\
Cost & + & + & - & + & $\mathrm{P}$ & - & $\mathrm{P}$ \\
Size & + & - & + & + & $\mathrm{P}$ & + & $\mathrm{E}$ \\
Foot print & + & + & + & + & $\mathrm{P}$ & + & + \\
Gearbox requirement & - & - & $\mathrm{E}$ & - & $\mathrm{E}$ & + & $\mathrm{E}$ \\
Converter size & + & $\mathrm{E}$ & - & + & + & + & + \\
Efficiency & - & + & + & + & + & + & $\mathrm{E}$ \\
Reliability & + & + & + & - & + & + & + \\
Maintenance & - & - & + & - & + & + & + \\
Noise level & - & + & + & - & + & + & + \\
Fault detection & - & - & - & - & + & + & $\mathrm{E}$ \\
Power factor & - & + & + & + & + & + & $\mathrm{E}$ \\
Power quality & - & + & + & + & + & + & $\mathrm{E}$ \\
Power range & + & - & $\mathrm{E}$ & - & $\mathrm{E}$ & - & + \\
Simple structure & + & - & + & + & - & + & + \\
Reduced head-mass & - & - & + & + & $\mathrm{P}$ & + & $\mathrm{E}$
\end{tabular}

E Excellent, + Good, - Fair, $P$ Poor 
induction generator models has declined after 1997 with the introduction of DFIGs with the variable speed feature. Since late 2000, DFIGs were the leading concept with $85 \%$ of the market share reported in 2008 [31,58]. Different types of SGs, mainly the PMSGs and EESGs, altered little in the period from 1995 to 2004 [57], but they have had a constant slow increase in the wind turbine market [31]. The interest in offshore wind turbines with the requirement of having a very large capacity, robust, and reliable generator has made different types of SGs more interesting on the market. As mentioned in Sect. 2.2.3, the feasibility of using HTS generators in DD wind turbines has been recently studied and it is expected to have wind turbines with HTS generators by 2014 [5,59]. However, PM generators have already been recognized as being the most efficient choice among the current generator designs on the market. The high efficiency of PM generators comes with a higher cost of materials compared with DFIGs. It has been argued that there is a trade-off between the high initial material cost of PMs and the low maintenance and part replacement cost over the lifetime of a wind turbine. It is seen that PM generators make the most economic sense among the current market viable generator concepts.

The worldwide large scale wind turbine generators with a capacity of $2.5 \mathrm{MW}$ and above are studied to better understand the trends of large wind turbine generators. Tables 2 and 3 show worldwide wind turbine manufacturers with different types of induction generators (including the SCIG and DFIG types) and SGs (including the EESG and PMSG types), respectively. The output rated power and rotor diameter of the wind turbines are written after the name of each manufacturer. Note that based on the environmental characteristics, mainly the wind speed/direction distribution at different wind farms, the wind turbine blades may be built in various diameters to capture enough wind power. More than $70 \%$ of the current large capacity (2.5 MW and above) wind turbines with induction generators have rated powers between
2.5 and $3 \mathrm{MW}$, and the largest capacity induction generator is the $6 \mathrm{MW}$ DFIG manufactured by Repower of Germany. More than $65 \%$ of the current large capacity $(2.5 \mathrm{MW}$ and above) wind turbines with different types of SGs have rated powers larger than $3 \mathrm{MW}$, and the current largest capacity synchronous generator is the $7.58 \mathrm{MW}$ EESG manufactured by Enercon of Germany, which is the world's largest wind turbine as of the beginning of 2012. EESGs were the main generator concept for variable speed wind turbines with a full scale converter; however, due to the disadvantages of EESGs, PMSGs have been drawing more attention and interest on the market $[31,60]$.

DFIGs as the current market leader have been used over the last decade to increase the average installed turbine size over time, allowing for higher rated wind turbines to be economically feasible. DFIGs are made of low cost steel parts, which keep the installation cost low, but require the low cost parts to be switched out often to maintain reliability. The global market shares of PMSG and EESG concepts have never exceeded $22 \%$, but their contributions in the wind power industry are increasing rapidly in recent years [31]. The requirements for having larger capacity wind turbines and capturing wind power in regions with lower annual mean wind speeds, together with the grid connection requirements, make the PMSG and EESG concepts more interesting. PM generators mostly use iron magnets that are more expensive than the steel parts of DFIGs, but have higher reliability because they have fewer moving parts. Iron, however, is not the most efficient material to use for PM generators. Copper, a much lighter material, provides a better magnetic field and conductivity. These benefits come at a higher material cost compared with iron, which is the current barrier for PMs being the dominant generator topology.

While the largest barrier for PMSGs is the difference in cost compared with DFIGs, the increase in efficiency has the potential to justify it, and PMSGs are most extensively used in large capacity (above $3 \mathrm{MW}$ ) commercial-scale onshore
Table 2 Large wind turbines with induction generators on the market

\begin{tabular}{llll}
\hline Manufacturer & Power/rotor diameter & Manufacturer & Power/rotor diameter \\
\hline Repower & $6.0 \mathrm{MW} / 126 \mathrm{~m}$ & Siemens & $3.0 \mathrm{MW} / 101 \mathrm{~m}$ \\
Bard & $5.0 \mathrm{MW} / 122 \mathrm{~m}$ & Acciona & $3.0 \mathrm{MW} / 100-116 \mathrm{~m}$ \\
Repower & $5.0 \mathrm{MW} / 126 \mathrm{~m}$ & Creative & $3.0 \mathrm{MW} / 103.4-100 \mathrm{~m}$ \\
Windtec & $5.0 \mathrm{MW} / 127-140 \mathrm{~m}$ & Guodian & $3.0 \mathrm{MW} / 100 \mathrm{~m}$ \\
Vestas & $4.5 \mathrm{MW} / 120 \mathrm{~m}$ & Windtec & $3.0 \mathrm{MW} / 91-112 \mathrm{~m}$ \\
Siemens & $3.6 \mathrm{MW} / 107-120 \mathrm{~m}$ & Vestas & $2.75 \mathrm{MW} / 100 \mathrm{~m}$ \\
Repower & $3.4 \mathrm{MW} / 104 \mathrm{~m}$ & Vestas & $2.6 \mathrm{MW} / 100 \mathrm{~m}$ \\
Repower & $3.2 \mathrm{MW} / 114 \mathrm{~m}$ & Fuhrlander & $2.5 \mathrm{MW} / 80-104 \mathrm{~m}$ \\
Vestas & $3.0 \mathrm{MW} / 90-112 \mathrm{~m}$ & Nordex & $2.5 \mathrm{MW} / 80-100 \mathrm{~m}$ \\
GE & $3.0 \mathrm{MW} / 104 \mathrm{~m}$ & W2E & $2.5 \mathrm{MW} / 90-113 \mathrm{~m}$ \\
Ecotecnia & $3.0 \mathrm{MW} / 100-110 \mathrm{~m}$ & Eviag & $2.5 \mathrm{MW} / 90-100 \mathrm{~m}$ \\
\hline
\end{tabular}


Table 3 Large wind turbines with SGs on the market

\begin{tabular}{llll}
\hline Manufacturer & Power/rotor diameter & Manufacturer & Power/rotor diameter \\
\hline Enercon & $7.58 \mathrm{MW} / 132 \mathrm{~m}$ & Shandong & $3.0 \mathrm{MW} / 100-113 \mathrm{~m}$ \\
GE & $6.0 \mathrm{MW} / 150 \mathrm{~m}$ & W2E & $3.0 \mathrm{MW} / 128 \mathrm{~m}$ \\
Alstom & $6.0 \mathrm{MW} / 150 \mathrm{~m}$ & Lagerway & $3.0 \mathrm{MW} / 90 \mathrm{~m}$ \\
Siemens & $6.0 \mathrm{MW} / 154 \mathrm{~m}$ & Leitwind & $3.0 \mathrm{MW} / 92.7-101 \mathrm{~m}$ \\
Nordex & $6.0 \mathrm{MW} / 150 \mathrm{~m}$ & Windtec & $3.0 \mathrm{MW} / 91-112 \mathrm{~m}$ \\
Multibird & $5.0 \mathrm{MW} / 116-135 \mathrm{~m}$ & GE & $2.75 \mathrm{MW} / 100-103 \mathrm{~m}$ \\
Creative & $5.0 \mathrm{MW} / 126 \mathrm{~m}$ & Avantis & $2.5 \mathrm{MW} / 93.2 \mathrm{~m}$ \\
Enercon & $4.5 \mathrm{MW} / 114 \mathrm{~m}$ & Goldwind & $2.5 \mathrm{MW} / 90-100 \mathrm{~m}$ \\
Nordex & $4.0 \mathrm{MW} / 110-113 \mathrm{~m}$ & Kenersys & $2.5 \mathrm{MW} / 100 \mathrm{~m}$ \\
Creative & $3.6 \mathrm{MW} / 115-126 \mathrm{~m}$ & Lagerway & $2.5 \mathrm{MW} / 90-93 \mathrm{~m}$ \\
Mervento & $3.6 \mathrm{MW} / 118 \mathrm{~m}$ & Leitwind & $2.5 \mathrm{MW} / 104.1 \mathrm{~m}$ \\
WinWind & $3.0 \mathrm{MW} / 90-109 \mathrm{~m}$ & M Torres & $2.5 \mathrm{MW} / 90-109 \mathrm{~m}$ \\
Blaster & $3.0 \mathrm{MW} / 100 \mathrm{~m}$ & Clipper & $2.5 \mathrm{MW} / 89-100 \mathrm{~m}$ \\
Doosan & $3.0 \mathrm{MW} / 91.3 \mathrm{~m}$ & Powerwind & $2.5 \mathrm{MW} / 90-100 \mathrm{~m}$ \\
Fuhrlander & $3.0 \mathrm{MW} / 120.6 \mathrm{~m}$ & Samsung & $2.5 \mathrm{MW} / 90-99.8 \mathrm{~m}$ \\
Guodian & $3.0 \mathrm{MW} / 100-108 \mathrm{~m}$ & GE & $2.5 \mathrm{MW} / 100 \mathrm{~m}$ \\
\hline
\end{tabular}

and offshore wind turbines. At high rated power levels, the unscheduled maintenance cost of worn-out generators is too high with offshore wind turbines, which requires expensive equipment and additional time, compared with onshore wind turbines. Under these two scenarios, the initial higher cost of PMSGs compared with DFIGs is often a justified trade-off for the increased reliability and efficiency of PMSGs. By comparing Tables 2 and 3, it is obvious that PMSGs are the main concept used in large capacity wind turbines. While more than $70 \%$ of the current large capacity (2.5 MW and above) wind turbines with induction generators have a rated power between 2.5 and $3 \mathrm{MW}$, the shares of large capacity wind turbines with SGs in the same range is just $35 \%$. It shows that different types of SGs, especially PMSGs, are market leaders in very large capacity (above $3 \mathrm{MW}$ ) wind turbines. The other result of comparing Tables 2 and 3 is the difference in the required rotor diameters for wind turbines with induction and synchronous generators. It is seen that wind turbines with output rated powers of $3 \mathrm{MW}$ and above with SGs generally have larger rotor diameters compared with those with induction generators. Designing and manufacturing larger, lighter, and more efficient rotor blades are still one of the challenges in capturing more wind power.

Table 4 shows market shares of wind turbines in percent from different manufacturers since 2005 [1,4-7,59,61]. Vestas is the pioneer in the market with its product range from 1 to $4.5 \mathrm{MW}$. However, its market share has decreased from $34.1 \%$ in 2004 to $12.9 \%$ in 2011 . More interest in the wind power industry in recent years has attracted more companies to join it, which has made it to be more competitive than before. There are several companies that have joined the top ten lists; Sinovel is one of them, and it has increased its market share from $3.4 \%$ in 2007 to $9.0 \%$ in 2011 . There are some companies that have kept a constant market portion in these years. For instance, Siemens has had the least changes in the market share; $6.1 \%$ in $2005,7.1 \%$ in $2007,5.9 \%$ in 2009 , and $6.3 \%$ in 2011 . However, there are other companies, such as Mitsubishi, have lost their places in the top ten list in these years. Finally, amazing increase in the involvement in the wind power industry by other wind turbine manufacturers in these years can be seen from Table 4 . These smaller companies had $5 \%$ of the market in 2005 , but this number is increased to $21 \%$ in 2011 . These rapid growth rates make the short and long term goals in expanding the wind power industry possible.

New generator technologies with lower cost and more reliable and compact design have made it possible to manufacture very large capacity generators, especially for offshore wind turbine applications. Table 5 shows four large capacity wind turbines that are expected to be installed in the next few years. Vestas has proposed its state-of-the-art offshore wind turbine, V-164 with a PMSG [62]. Gaemsa obtained its $5 \mathrm{MW}$ offshore wind turbine design certificate in January 2012, and is expected to install the first machines at wind farms by 2014 [63]; it also plans to design higher capacity (7-8 MW) offshore wind turbines in the future. Windtec has introduced a new generation offshore wind turbine, SeaTitan with a HTS generator with efficiency up to $96 \%$ and a very large rotor diameter of $190 \mathrm{~m}$ [52]. Besides the improvements in the generator designs, Clipper proposed a new drivetrain design with multiple smaller generators instead of a large one to increase the reliability and efficiency [64]. Its $10 \mathrm{MW}$ offshore wind turbine with four generators in parallel was expected to be installed in UK by the end of 2012 [65], but it stopped the development of the project due to financial crisis. 
Table 4 Top ten and other wind turbine manufacturers and their market shares during 2005-2011

\begin{tabular}{|c|c|c|c|c|c|c|c|c|}
\hline & \multicolumn{2}{|l|}{2005} & \multicolumn{2}{|l|}{2007} & \multicolumn{2}{|l|}{2009} & \multicolumn{2}{|l|}{2011} \\
\hline & Manufacturer & $\%$ & Manufacturer & $\%$ & Manufacturer & $\%$ & Manufacturer & $\%$ \\
\hline 1 & Vestas & 27.9 & Vestas & 22.8 & Vestas & 12.5 & Vestas & 12.9 \\
\hline 2 & GE Wind & 17.7 & GE Wind & 16.6 & GE Wind & 12.4 & Sinovel & 9.0 \\
\hline 3 & Enercon & 13.2 & Gamesa & 15.4 & Sinovel & 9.2 & Goldwind & 8.7 \\
\hline 4 & Gamesa & 12.9 & Enercon & 14 & Enercon & 8.5 & Gamesa & 8.0 \\
\hline 5 & Suzlon & 6.1 & Suzlon & 10.5 & Goldwind & 7.2 & Enercon & 7.8 \\
\hline 6 & Siemens & 5.5 & Siemens & 7.1 & Gamesa & 6.7 & GE Wind & 7.7 \\
\hline 7 & RePower & 3.1 & Acciona & 4.4 & Dongfang & 6.5 & Suzlon & 7.6 \\
\hline 8 & Nordex & 2.6 & Goldwind & 3.4 & Suzlon & 6.4 & United Power & 7.4 \\
\hline 9 & Ecotecnia & 2.1 & Nordex & 3.4 & Siemens & 5.9 & Siemens & 6.3 \\
\hline \multirow[t]{2}{*}{10} & Mitsubishi & 2 & Sinovel & 3.4 & RePower & 3.4 & Mingyang & 3.6 \\
\hline & Others & 5 & Others & 10.5 & Others & 18.5 & Others & 21 \\
\hline
\end{tabular}

Table 5 Four large wind turbines to be installed in the next few years

\begin{tabular}{lll}
\hline Manufacturer & Power/rotor diameter & Year of production \\
\hline Vestas & $7.0 \mathrm{MW} / 164 \mathrm{~m}$ & 2015 \\
Gamesa & $5.0 \mathrm{MW} / 128 \mathrm{~m}$ & 2015 \\
Windtec & $10.0 \mathrm{MW} / 190 \mathrm{~m}$ & 2014 \\
Clipper & $10.0 \mathrm{MW} / 150 \mathrm{~m}$ & 2012 \\
\hline
\end{tabular}

Employing larger capacity generators for offshore wind turbines is limited by structural and power control restrictions $[23,27,66]$. For instance, while a DD wind turbine such as the Enercon E-126 7.5 MW wind turbine does not have a gearbox, it has a very large and expensive drivetrain structure [43]; the poor power quality control and design issues, such as unbalanced generator torque distribution on the gearbox, led to the failure of the $2.5 \mathrm{MW}$ Clipper Windpower wind turbines at the 20 MW Steel Winds wind farm in the upstate New York, as well as in Iowa and Minnesota in 2008 [67]. Recent studies on multiple-generator drivetrain (MGD) technologies propose a new MGD with an automatic switch to address the design issues of the current MGD and provide a better performance compared with the current and conventional drivetrain technologies in terms of efficiency, reliability, and expanded operational range $[68,69]$. To expand the operational range of onshore wind turbines, another variable electromotive-force generator (VEG) design with an adjustable overlap between the rotor and stator is investigated [70,71]; wind turbines with the VEG feature can be employed in areas having a low annual mean wind speed with high fluctuations throughout a year [72].

\section{Conclusion}

By comparing various types of generators, it is found that DFIGs are the current market leader with more than $80 \%$ share on the market. However, due to the need of implementing larger capacity wind turbines, PMSGs have been drawing more attention and their market share has been increasing in recent years. The advantages of new SGs with the second generation of HTS wires, in terms of having a smaller size and higher output power quality, and being more reliable and cost effective, show the potential of replacing PMSGs and DFIGs with HTS generators and manufacturing wind turbines with very large rotor diameters in future years.

The significant increase of smaller company shares in designing and manufacturing wind turbines (from $5 \%$ in 2005 to more than $21 \%$ in 2011) shows an amazing worldwide interest in getting involved in different aspects of wind power production. The rapid growth of wind turbine generator technologies, together with worldwide support for implementation of wind energy projects, will produce more green energy and lead to more independency from conventional energy sources.

\section{References}

1. Solyali D, Redfern MA (2009) Have wind turbines stop maturing? In: IEEE 44th International Universities, Power Engineering Conference (UPEC)

2. Carlin PW, Laxson AS, Muljadi EB (2001) The history and state of the art of variable-speed wind turbine technology. National Renewable Energy Laboratory, NREL/TP-500-28607, Golden

3. Goudarzi N, Zhu WD, Bahari H (2013) Wind energy conversion: the potential of a novel ducted turbine for residential and commercial applications. In: Proceedings of the ASME (2013) International Mechanical Engineering Congress \& Exposition. San Diego, California, USA (to be published)

4. BTM Consult Reports (2005) International wind energy development world market updates 2004 (forecast 2005-2009). BTM Consult ApS, Ringkobing

5. BTM Consult Reports (2006) International wind energy development world market updates 2005 (forecast 2007-2011). BTM Consult ApS, Ringkobing 
6. BTM Consult Reports (2008) International wind energy development world market updates 2007 (forecast 2008-2012). BTM Consult ApS, Ringkobing

7. Global Wind Energy Reports (2013) Global wind statistics 2012. Global Wind Energy Council (GWEC), Brussels

8. World Wind Energy Association Reports (2011) World wind energy report 2010. WorldWind Energy Association (WWEA), Bonn

9. Global Wind Energy Reports (2012) Global wind energy outlook 2012. Global Wind Energy Council (GWEC), Brussels

10. Boldea I (2006) Synchronous generators (the electric generators handbook), Chap 2. Taylor and Francis group, USA, pp 1-28

11. Goudarzi N (2011) Aerodynamic and electromagnetic modeling and analysis of a variable torque generator for wind turbine applications. Master Thesis, Department of Mechanical Engineering, University of Maryland Baltimore County, Baltimore, MD, USA

12. Badrzadeh B (2011) Qualitative performance assessment of semiconductor switching device, converter and generator candidates for $10 \mathrm{MW}$ offshore wind turbine generators. Wind Energy 14(3):425448

13. Hansen LH, Helle L, Blaabjerg F, Ritchie E, Munk-Nielsen S, Binder H, Sorensen P, Bak-Jensen B (2001) Conceptual survey of generators and power electronics for wind turbines. Riso-r1205(EN), Riso National Laboratory, Roskilde

14. Soens J (2005) Impact of wind energy in a future power grid. Ph.D. Dissertation, ISBN 90-5682-652-2, Wettelijk depot, UDC 621.548

15. Polinder H, Bang DJ, Chen Z (2007) Concept report on generator topologies, Mechanical and Electromagnetic Optimization. Delft University of Technology and Aalborg University, Deliverable Number: D 1B2.b.1

16. Chen Z (2005) Issues of connecting wind farms into power systems. In: Proceedings of Transmission and Distribution Conference \& Exhibition: Asia and Pacific, 2005 IEEE/PES

17. Akhmatov V (2007) Induction generators for wind power. MultiScience, Brentwood

18. Henderson DS (1996) Synchronous or induction generators? - the choice for small scale generation. In: International Conference on Opportunities and Advances in International Electric Power Generation, pp 146-149

19. Muller H, Poller M, Basteck A, Tilscher M, Pfister J (2006) Grid compatibility of variable apeed wind speed turbines with directly coupled synchronous generator and hydro-dynamically controlled gearbox. VOITH Turbo. In: 6th International Workshop on LargeScale Integration of Wind Power and Transmission Networks for Offshore Wind Farms, Delft, NL

20. Ameli MT, Moslehpour S, Mirzaie A (2008) Feasibility study for replacing asynchronous generators with synchronous generators in wind farm power stations. In: IAJC-IJME International Conference

21. Arai J, Dei T, Takai S, Takagi K (2009) Study on application of fixed speed synchronous generator for wind power generation. In: The International Conference on Electrical Engineering

22. Wang F, Bai J, Hou Q, Pan J (2005) Design features of low speed permanent magnet generator direct driven by wind turbine. In: Proceedings of the 8th International Conference on Electrical Machines and Systems, ICEMS 2005, vol 2

23. Bywaters G, John V, Lynch J, Mattila P, Nortor G, Stowell J, Salata M, Labath O, Chertok A, Hablanian D (2004) Northern power systems WindPACT drive train alternative design study report. National Renewable Energy Laboratory (NREL), NREL/SR-50035524, Golden

24. Grauers A (1996) Design of direct-driven permanent-magnet generators for wind turbines. Ph.D. Dissertation, Chalmers University of Technology, Göteborg, Sweden

25. Dubois M (2004) Optimized permanent magnet generator topologies for direct drive wind turbines. Ph.D. Dissertation, Delft University of Technology, Delft, NL
26. Lampola P (2000) Directly driven, low-speed permanent-magnet generators for wind power applications. Ph.D. Dissertation, Helsinki University of Technology, Finland

27. Poore R, Lettenmaier T (2003) Alternative design study report: WindPACT advanced wind turbine drive train designs study. National Renewable Energy Laboratory (NREL), NREL/SR-50033196, Golden

28. Polinder H, Pijl FFA, De Vilder GJ, Tavner P (2006) Comparison of direct-drive and geared generator concepts for wind turbine. IEEE Trans Energy Convers 21:725-733

29. Semken RS, et al (2012) Direct-drive permanent magnet generators for high-power wind turbines: benefits and limiting factors. Renew Power Gener IET 6(1)

30. Aleksashkin A, Mikkola A (2008) Literature review on permanent magnet generators design and dynamic behavior. Lappeenranta University of Technology, Lappeenranta. ISBN $1459-2932$

31. Gupta A, Jain DK, Dahiya S (2012) Some investigations on recent advances in wind energy conversion systems. IPCSIT Press, Singapore

32. Eckels P, Snitcher G (2004) 5 MW High temperature superconductor ship propulsion motor design and test results. Naval Eng $\mathbf{J}$ 117(4):31-36

33. Al-Bahadly I (2011) Wind turbines. InTech, Rijeka, pp 623-638, Chap 27. ISBN 978-953-307-221-0

34. Pellegrino GM, Villata F, Guglielmi P, Vagati A (2003) Design of direct-drive, low-speed PM machines. In: Industry Applications Conference, 38th IAS Annual Meeting. vol 2, pp 1421-1428

35. Cheng KWE, Lin JK, Bao YJ, Xue XD (2009) Review of wind generating system. In: 8th International Conference Control and Management (APSCOM)

36. Mittal R, Sandu KS, Jain DK (2009) Isolated variable speed driven PMSG for WECS. Int J Eng Tech 1(3)

37. Bang D, Polinder H, Shrestha G, Ferreira JA (2008) Review of generator systems for direct-drive wind turbines. Electrical Power Processing/ DUWIND. Delft University of Technology, Delft

38. Li H, Chen Z (2008) Overview of different wind generator systems and their comparisons. Renew Power Gener 2(2):123-138

39. Haque ME, Muttaqi KM, Nagnevitsky M (2008) A novel control strategy for a variable speed wind turbine with a permanent magnet synchronous generator. IEEE

40. Hansen AD, Michalke G (2008) Modeling and control of variablespeed multi-pole permanent magnet synchronous generator wind turbine. Wind Energy 11(5):537-554

41. Ackerman T (2006) Wind power in power systems. Wiley, London

42. Bose BK (2006) Power electronics and motor drives: advances and trends. Academic press, London

43. Stander JN, Venter G, Kamper MJ (2011) Review of direct-drive radial flux wind turbine generator mechanical design. Wind Energy 15(3):459-472

44. Siegfriedsen S, Bohmeke G (1998) Multibird technology—a significant step to multi-megawatt wind turbines. Wind Energy $1(2): 89-100$

45. Schiferl R (2008) High-temperature superconducting synchronous motors: economic issues for industrial applications. IEEE Trans Ind Appl 44(5):1376-1384

46. Lewis C, Muller J (2007) A direct drive wind turbine HTS generator. In: IEEE Power Engineering Society General Meeting, IEEE Tampa, FL, USA

47. Kalsi SS, Weeber K, Takesue H, Lewis C, Neumueller HW, Blaugher RD (2004) Development status of rotating machines employing superconducting field windings. IEEE Proc 92(10): $1688-1704$

48. Kalsi SS (2002) Development status of superconducting rotating machines. Power Engineering Society Winter Meeting. IEEE 1:401-403 
49. Hull JR, Murakami M (2004) Applications of bulk high temperature superconductors. IEEE Proc 92(10):1705-1718

50. Masson PJ, Luongo CA (2005) High power density superconducting motor for all-electric aircraft propulsion. IEEE Trans Appl Supercond 15(2):2226-2229

51. Superczynski MJ, Waltman DJ (1997) Homopolar motor with high temperature superconductor field windings. IEEE Trans Appl Supercond 7(2):513-518

52. Nakamura T, Miyake H, Ogama Y, Morita G, Muta I, Hoshino $\mathrm{T}$ (2006) Fabrication and characteristics of HTS induction motor by the Use of B1-2223/Ag squirrel-cage rotor. IEEE Trans Appl Supercond 16(2)

53. Windtec Solutions (2012) SeaTitan 10 MW. http://www.amsc.com/ documents/seatitan-10-mw-wind-turbine-data-sheet/

54. Gamble B, Snitchler G, Kalsi SS (2006) HTS generator topologies. In: Power Engineering Society General Meeting, IEEE

55. Chen Y, Pillay P, Khan A (2005) PM wind generator topologies. IEEE Transactions Ind Appl 41(6):1619-1626

56. Dubois MR, Polinder H, Ferreira JA (2000) Comparison of generator topologies for direct-drive wind turbines. In: IEEE Nordic Workshop on Power and Industrial Electronics (NORPIE), Denmark

57. Widya S (2006) Design, optimization, construction and test of rareearth permanent-magnet electrical machines with new topology for wind energy applications. Ph.D. Dissertation, Technical University of Berlin, Berlin, Germany

58. Hansen AD, Hansen LH (2007) Wind turbine concept market penetration over 10 years (1995-2004). Wind Energy J 10(1):81-97

59. Schinas NA, Vovos NA (2007) An autonomous system supplied only by a pitch-controlled variable-speed wind turbine. IEEE Trans Energy Convers 22(2):325-331

60. BTM Consult Reports (2012) International wind energy development world market update 2011 (Forecast 2012-2016). BTM Consult ApS, Ringkobing

61. Senjyu T, Kikunaga Y, Yona A, sekiene H, Saber AY (2008) Coordinate control of wind turbine and battery in wind power generator system. In: Power and Energy Society Meeting

62. REN 21 Reports (2011) Renewable 2012, global status report. Renewable Energy Policy Network for the 21st Century

63. Vestas Wind Systems (2011) V164-7.0 MW. http://nozebra. ipapercms.dk/Vestas/Communication/Productbrochure/V16470M W/V16470MW/
64. Gamesa (2012) G128-5.0 MW. http://www.gamesacorp.com /recursos/doc/productos-servicios/aerogeneradores/catalogo-offs hore-eng.pdf

65. Mikhail A, Petch D (2005) Clipper Liberty series: advanced low wind speed technology. In: Presented in California Wind Energy Collaborative Forum, Davis, CA, USA

66. Dvorak P (2010) Britanica breaks the 9 MW barriers. Windpower Engineering Magazine, pp 36-42, http://www.clipperwind.com/ pdf/wpe_Britannia.pdf

67. Baroudi JA, Dinavahi V, Knight AM (2005) A Review of power converter topologies for wind generators. Electric Machines and Drives. In:IEEE International Conference on, San Antonio, TX, USA

68. Buster J (2008) Clipper wind turbine gear failures stop 'Steelwinds' in Lackawanna, New York. Regional Economics Action Links North East Ohio. http://realneo.us/blog/jeff-buster/wind-turbinegears-are-problem-in-lackawanna

69. Goudarzi N, Zhu WD, Pavlak A (2012) Analysis of multiplegenerator drivetrain configuration in wind turbines. In: American Wind Energy Association (AWEA) Offshore WINDPOWER Conference and Exhibition, Virginia Beach, VA, USA

70. Goudarzi N, Zhu WD (2013) Offshore and onshore wind energy conversion: the potential of a novel multiple-generator drivetrain. Key Eng Mater

71. Zhu WD, Goudarzi N, Wang XF, Kendrick P (2012) Development of a variable electromotive-force generator for a wind turbine. In: Proceedings of the ASME International Mechanical Engineering Congress \& Exposition, Houston, Texas, USA

72. Zhu WD, Goudarzi N, Wang XF (2013) Development of an active control system for a variable electromotive-force generator with applications to wind turbines, ships, and hybrid vehicles. In: Proceedings of the ASME (2013) International Mechanical Engineering Congress \& Exposition. California, USA (to be published)

73. Goudarzi N, Zhu WD, Bowers R (2012) Aerodynamic and electromagnetic analysis of a variable electromotive-force generator for a wind turbine. In: Proceedings of the ASME International Mechanical Engineering Congress \& Exposition, Houston, Texas, USA 